\title{
Mechanism of Resistance to Complement-mediated Killing of Bacteria Encoded by the Salmonella typhimurium Virulence Plasmid Gene rck
}

\author{
Edwin J. Heffernan, * Sharon Reed, * Jim Hackett, Joshua Fierer, ** Chantal Roudier, * and Donald Guiney * \\ *Department of Medicine, University of California, San Diego, California 92103; ${ }^{\ddagger}$ Veterans Administration Medical Center, \\ La Jolla, California 92161; and ${ }^{\S}$ Waite Agricultural Research Institute, Glen Osmond, South Australia 5064
}

\begin{abstract}
We find that pADEO16, a recombinant cosmid carrying the rck gene of the Salmonella typhimurium virulence plasmid, when cloned into either rough or smooth Escherichia coli and Salmonella strains, confers high level resistance to the bactericidal activity of pooled normal human serum. The rck gene encodes a 17-kD outer membrane protein that is homologous to a family of virulence-associated outer membrane proteins, including pagC and Ail. Complement depletion, $\mathrm{C} 3$ and $\mathrm{C5}$ binding, and membrane-bound $\mathrm{C} 3$ cleavage products are similar in strains with and without rck. Although a large difference in $\mathrm{C} 9$ binding was not seen, trypsin cleaved $55.7 \%$ of bound ${ }^{125} \mathrm{I}-\mathrm{C} 9$ counts from rough $S$. typhimurium with pADEO16, whereas only $\mathbf{2 6 . 4 \%}$ were released from $S$. typhimurium with K2011, containing a mutation in rck. The majority of $\mathrm{C} 9$ extracted from rck strain membranes sediments at a lower molecular weight than in strains without rck, suggesting less $C 9$ polymerization. Furthermore, SDS-PAGE analysis of gradient peak fractions indicated that the slower sedimenting C9-containing complexes in rck strains did not contain polymerized C9 typical of the tubular membrane attack complex. These results indicate that complement resistance mediated by Rck is associated with a failure to form fully polymerized tubular membrane attack complexes. (J. Clin. Invest. 1992.90:953-964.) Key words: complement resistance gram-negative bacteria • outer membrane proteins • plasmids • virulence
\end{abstract}

\section{Introduction}

Resistance to complement-mediated killing or serum resistance is an established virulence trait of Gram-negative bacteria (for reviews see references 1 and 2). Enterobacteriaceae isolated from blood cultures are nearly always serum resistant $(3,4)$, as are Neisseria gonorrhoeae strains causing disseminated gonococcal infection (5). Components of the bacterial cell surface, including capsules, LPS, and outer membrane proteins, have been shown to affect the interaction between complement and various Gram-negative organisms (for review see reference 2).

A major determinant of serum resistance of Salmonellae appears to be long-chain LPS, as shown by the elegant studies of Joiner and his colleagues $(6,7)$. In Salmonella minnesota, the terminal complement $\mathrm{C} 5 \mathrm{~b}-9$ membrane attack complex

Address correspondence to Edwin J. Heffernan, M.D., Department of Medicine, University of California San Diego Medical Center, 8416, 225 Dickinson Street, San Diego, CA 92103.

Received for publication 30 November 1990 and in revised form 16 March 1992.

The Journal of Clinical Investigation, Inc.

Volume 90, September 1992, 953-964
(MAC) $)^{1}$ forms at a distance from the hydrophobic regions of the outer membrane because of the preferential deposition of $\mathrm{C} 3$ on the long LPS O-antigen side chains. The MAC is then shed without disrupting the integrity of either the inner or outer bacterial membranes. Polysaccharide capsules, important in the serum resistance of other Gram-negative bacteria $(8,9)$, appear to play little role in nontyphoidal Salmonella serotypes.

Several nontyphoid Salmonella serotypes associated with invasive disease contain virulence plasmids that are required for the establishment of a lethal, systemic infection in experimental animals. These Salmonellae include the host-adapted serotypes dublin, choleraesuis, and gallinarium-pullorum, as well as the broad host range typhimurium and enteritidis strains (for review see reference 10). Molecular genetic studies have defined an 8-kb region of the $S$. typhimurium and $S$. dublin virulence plasmids required for virulence in inbred mice $(10,11)$. Several studies have also reported an effect of virulence plasmid-encoded loci on the serum resistance phenotype. The $S$. typhimurium plasmid contains a traT-like locus, specifying an outer membrane protein very similar to those encoded by F-like plasmid conjugation systems. This traT protein confers complement resistance in certain $E$. coli and Salmonella strains (12). A second locus from S. typhimurium, $r s k$, does not by itself encode serum resistance but appears to enhance the ability of smooth $S$. typhimurium to grow in serum. The $r s k$ region does not encode a protein but contains a series of imperfectly repeated 10 -bp sequences $(13,14)$. A third locus of complement resistance has recently been described on the $S$. dublin plasmid and appears to restore synthesis of a complete $\mathrm{O}$ antigen in certain partially rough mutants of $S$. dublin (15-17). These studies suggest that various elements of the Salmonella virulence plasmids may be capable of restoring serum resistance under certain specific conditions, especially in the setting of altered LPS.

A fourth complement resistance locus on the $S$. typhimurium plasmid was identified and cloned by Hackett and coworkers (18). They found that a $2.1-\mathrm{kb}$ ClaI/PstI fragment of the $S$. typhimurium virulence plasmid, when cloned into a multicopy cosmid construct they designated pADEO16, was capable of restoring high-level serum resistance to a rough serum-sensitive $E$. coli $\mathrm{K}-12$ strain and to a rough, plasmidcured $S$. typhimurium strain. In addition, they found that expression of the serum resistance phenotype by pADEO16 was associated with the production of an outer membrane protein but not with restoration of wild-type LPS. The mechanisms by which pADEO16 was able to confer serum resistance upon these $E$. coli and Salmonella strains were not elucidated.

1. Abbreviations used in this paper: DPBS, Dulbecco's PBS; HI, heatinactivated decomplemented sera; MAC, membrane attack complex; VBS ++ , veronal-buffered saline with $0.15 \mathrm{mM} \mathrm{CaCl}_{2}$ and $0.5 \mathrm{mM}$ $\mathrm{MgCl}_{2} ; \mathrm{VBSG}++, \mathrm{VBS}++$ containing $0.1 \%$ gelatin. 
We have recently determined the nucleotide sequence of the $S$. typhimurium serum resistance gene present in pADEO16 (designated $r c k$, for "resistance to complement killing") and have shown that its $17-\mathrm{kD}$ outer membrane protein product Rck is responsible for the serum resistance phenotype (19). In addition, we found that Rck is homologous to a family of virulence-associated outer membrane proteins expressed in gram-negative bacteria, including $p a g C$, required by $S$. typhimurium for survival in macrophages and for virulence in mice $(20,21)$, and Ail, a product of the Yersinia enterocolitica chromosome capable of mediating bacterial adherence and invasion of epithelial cell lines (22-24).

We find that $r c k$, in pADEO16, is capable of producing high level serum resistance when cloned in a variety of rough and smooth $E$. coli and Salmonella strains, characteristics not reported for other Salmonella virulence plasmid serum resistance loci. The association of $r c k$ in pADEO16 with serum resistance offered an opportunity to investigate the means by which a single outer membrane protein species interacts with the complement system to inhibit killing of Gram-negative bacteria. In this study we investigated the mechanism of $r c k$-mediated serum resistance.

\section{Methods}

Bacterial strains. The characteristics of the strains used are described in Table I.

Plasmids and methods of gene transfer. The construction of the recombinant cosmid pADEO16 ( TcR, KmR, pBR322, and R6K replicons) containing a 2.1-kb fragment from the $S$. typhimurium virulence plasmid has been described previously (18). A single gene in this fragment, designated $r c k$, encodes a $17-\mathrm{kD}$ outer membrane protein and is responsible for the serum resistance phenotype (19); construct pK2011 (previously designated pADEO16 $\Delta \mathrm{KpnI}_{2011}$ ) contains a 4-bp deletion in the $r c k$ gene that truncates the outer membrane protein and does not encode the serum resistance phenotype, as previously described (19). Transformation of E. coli JA221 with pADEO16 and pK2011 was accomplished by standard methods using calcium chloride to prepare competent cells (25). Transfer of pADEO16 and pK2011 by conjugation from $E$. coli JA221 into E. coli and Salmonella strains was accomplished by a triparental mating system using a helper plasmid, pRK2073 (in E. coli MV12), capable of high frequency mobilization, as previously described (26); transconjugates were shown not to contain the helper plasmid pRK2073 by confirming sensitivity to trimethoprim $(100 \mu \mathrm{g} / \mathrm{ml})$. The presence of the desired plasmid and the absence of the helper plasmid was confirmed in all transformants and transconjugates by restriction endonuclease digests of plasmid DNA.
Curing of the S. typhimurium virulence plasmid. S. typhimurium $14028 \mathrm{~S}$ and $14028 \mathrm{R}$ were cured of the large virulence plasmid by use of the par-locus of Tinge and Curtiss (27) cloned on pYA2028. pYA2028 was transformed into the restriction-/modification $+S$. typhimurium strain LB5000. Clone analysis DNA isolated from LB5000 was subsequently transformed into $S$. typhimurium 14028 S and 14028 R. 10 colonies were obtained on penicillin plates $(400 \mu \mathrm{g} / \mathrm{ml})$. Each of these colonies were grown for 100 generations in L-broth containing 600 $\mu \mathrm{g} / \mathrm{ml}$ penicillin to allow segregation of the virulence plasmid. The cells were then grown for 50 generations without selection to allow spontaneous loss of pYA2028, plated on Luria broth agar, and replicaplated on penicillin plates. Cells that had lost penicillin resistance were analyzed by both clone analysis and colony hybridization, the latter using a 4-kb EcoRI portion of the virulence region as a probe (28); all colonies probed lacked any evidence of the wild-type virulence plasmid. The morphology, biochemical profile, and agglutination profile were found to be the same in both the wild-type parent and the plasmid-cured strains.

Serum sensitivity studies. Normal human serum was collected from 10 healthy volunteers, pooled, and stored at $-70^{\circ} \mathrm{C}$ until used (pooled normal human sera [PNHS]). Control sera were decomplemented by heating at $56^{\circ} \mathrm{C}$ for $30 \mathrm{~min}$ (heat-inactivated sera [HI]). Serum sensitivity studies were performed on a variety of $E$. coli and Salmonella strains using the Fothergill method (29). Serial 10-fold dilutions of mid log-phase bacterial suspensions in Dulbecco's phosphate-buffered saline (DPBS) were incubated for $60 \mathrm{~min}$ in 50\% PNHS at $37^{\circ} \mathrm{C}$ and then plated on tryptic soy agar. Serum sensitivity was calculated as the difference in CFUs surviving incubation in PNHS and in $\mathrm{HI}$ sera expressed in $\log$ base 10 , and designated log kill. Time-kill curves and studies of the effects of differing serum concentrations were performed in the same manner. A preliminary experiment showed there was no difference in serum sensitivity whether incubation was performed in air or $10 \% \mathrm{CO}_{2}(13,30)$; all subsequent assays were performed in air.

Complement activation studies. The consumption of total hemolytic activity (CH50) by E. coli 0111:B4 strains with and without pADEO16 was determined by incubating $1 \times 10^{9}$ bacteria in $1 \mathrm{ml}$ of $50 \%$ PNHS at $37^{\circ} \mathrm{C}$; control samples consisted of $50 \%$ PNHS alone. Aliquots were removed at $15,30,45$, and $60 \mathrm{~min}$, and the pellets and supernatants were separated by centrifugation. The total hemolytic activity in the resulting supernatants was determined by incubating sheep erythrocytes sensitized with rabbit anti-sheep antibody with dilutions of the supernatants for $60 \mathrm{~min}$ at $37^{\circ} \mathrm{C}$. The unlysed erythrocytes were then removed by centrifugation, and the hemoglobin in the supernatant was determined by optical density readings at $414 \mathrm{~nm}$ (31).

Complement components. Purified human C3, C5, and C9 were purchased from Quidel (San Diego, CA). The purified proteins were radiolabeled with ${ }^{125}$ I by the iodogen technique (32) to a specific activity of $1-2 \times 10^{6} \mathrm{cpm} / \mu \mathrm{g}$ of protein. Less than $20 \%$ of the hemolytic activity was lost during labeling as assayed with EAC14b cells (prepared by incubating sheep erythrocytes sensitized with rabbit anti-

Table I. Bacterial Strains, Characteristics, and Lipopolysaccharide Structure

\begin{tabular}{|c|c|c|c|}
\hline Strains & Characteristics & LPS & Reference \\
\hline E. coli $0111: \mathrm{B} 4$ & Wild-type, serum sensitive & Smooth & 63 \\
\hline E. coli JA221 & K-12; leuB, $\Delta \operatorname{trpE} 5$, lacY, recA, hsdR - , hsdM+ & Rough & 64 \\
\hline S. minnesota $\mathbf{S} 218$ & Wild-type, supplied by Luderitz & Smooth & 65 \\
\hline S. minnesota Ra & Derivative of $S 218$, lacks $O$ side chains & $\mathbf{R a}$ & 65 \\
\hline S. typhimurium $\mathrm{J} 42$ & Plasmid cured; recA1, srl::Tn5, leuB129, hisC527 & Rough & 18 \\
\hline $14028 \mathrm{~S}$ & S. typhimurium LT2 derivative, wild-type & Smooth & 66 \\
\hline C14028S & $14028 \mathrm{~S}$, cured of the virulence plasmid & Smooth & \\
\hline $14028 \mathrm{R}$ & Rough derivative of $14028 \mathrm{~S}$ & $\mathrm{Ra}$ & 67 \\
\hline C14028R & $14028 \mathrm{R}$, cured of the virulence plasmid & $\mathbf{R a}$ & \\
\hline
\end{tabular}


sheep hemolysin in $10 \%$ PNHS with $10 \mathrm{mg} / \mathrm{ml}$ of methylprednisone (33), $50 \mathrm{U} / \mathrm{ml} \mathrm{C2oxy} \mathrm{(34),} \mathrm{and} \mathrm{potassium} \mathrm{bromide-inactivated}$ serum ( 35 ) supplemented with C5 (Diamedix Corp., Miami, FL). C3b was produced by the cleavage of ${ }^{125} \mathrm{I}-\mathrm{C} 3$ with a 1:100 dilution (wt/wt) of tosylamide-phenylethylchloromethyl ketone-trypsin (Sigma Chemical Co., St. Louis, MO) in PBS for $8 \mathrm{~min}$ at room temperature, followed by the addition of a 10-fold excess of soybean trypsin inhibitor. The C9 neoantigen, consisting of fluid phase polymerized $\mathrm{C} 9$, was formed by the incubation of $20 \mu \mathrm{g}$ of unlabeled C9 with $2 \mu \mathrm{g}$ of ${ }^{125} \mathrm{I}-\mathrm{C} 9$ in the presence of $500 \mu \mathrm{M} \mathrm{ZnCl}_{2}$ (36).

Quantitative binding of $C 3, C 5$, and $C 9$. Purified human $\mathrm{C} 3, \mathrm{C} 5$, and $C 9$ were radiolabeled with ${ }^{125} \mathrm{I}$ by the iodogen method $(32)$ to a specific activity of $1-2 \times 10^{6} \mathrm{cpm} / \mu \mathrm{g}$ of protein. Bacteria in a final concentration of $2 \times 10^{8} / \mathrm{ml}$ were incubated in $20 \%$ PNHS or HI sera at $37^{\circ} \mathrm{C}$, to which ${ }^{125} \mathrm{I}$-labeled C3 $(7.0 \mu \mathrm{g} / \mathrm{ml}), \mathrm{C} 5(2.8 \mu \mathrm{g} / \mathrm{ml})$, or C9 $(3.2 \mu \mathrm{g} / \mathrm{ml})$ were added. At designated intervals, duplicate $70-\mu \mathrm{l}$ aliquots were layered over $200 \mu \mathrm{l}$ of $10 \%$ sucrose in veronal-buffered saline with $0.15 \mathrm{mM} \mathrm{CaCl}_{2}$ and $0.5 \mathrm{mM} \mathrm{MgCl}_{2}$ (VBS++), and the pellets and supernatants were separated by centrifugation at $12,500 \mathrm{~g}$ for $5 \mathrm{~min}$. Preliminary studies using microscopic evaluation, hemocytometer counts, and viability counts showed that at these bacteria/ serum ratios relatively little loss of either sensitive or resistant bacteria into the supernatants occurred $(<2 \%)$. The tips of the tubes containing the pellets were cut off and the counts bound determined using a gamma counter (model 1185; Searle Analytic, Chicago, IL). The molecules of $\mathrm{C} 3, \mathrm{C} 5$, or $\mathrm{C} 9$ specifically bound per $\mathrm{CFU}$ were calculated by subtracting the counts bound in HI sera ( $<1 \%$ of the total counts) and correcting for the specific activity of the labeled component, the ratio of the labeled to the unlabeled protein, and the number of initial bacteria (6).

$S D S-P A G E$. The structure of bound $\mathrm{C} 3$ and $\mathrm{C} 9$ was evaluated by SDS-PAGE (37). Bacterial strains with and without pADEO16 were incubated for $30 \mathrm{~min}$ in $20 \%$ PNHS containing ${ }^{125} \mathrm{I}$-labeled $\mathrm{C} 3$ or $\mathrm{C} 9$, as above. The pellets and supernatants were separated by centrifugation at $12,500 \mathrm{~g}$ for $5 \mathrm{~min}$ and the pellets washed twice with DPBS. Samples were reduced and denature by boiling for $3 \mathrm{~min}$ in 2.5\% 2-mercaptoethanol and $2 \%$ SDS in $0.1 \mathrm{M}$ Tris, $\mathrm{pH}$ 7.5. To release $\mathrm{C} 3$ molecules that were linked by ester bonds, identical pellets were resuspended in $10 \mu \mathrm{l}$ DPBS, $2.5 \mu \mathrm{l} 20 \% \mathrm{SDS}$, and $12.5 \mu \mathrm{l}$ of $50 \mathrm{mM}$ methylamine in $200 \mathrm{mM}$ sodium carbonate buffer, $\mathrm{pH} 11.0$; incubated at $37^{\circ} \mathrm{C}$ for 60 min (38); and the supernatant separated and reduced as above. Samples for $\mathrm{C} 3$ binding were electrophoresed by SDS-PAGE under reducing conditions using a 5-15\% gradient, and for C9 by using $2-12 \%$ gradients. Gels were dried and developed with Kodak XAR film at $-70^{\circ} \mathrm{C}$. Aliquots from peak fractions of sucrose density gradients containing ${ }^{125} \mathrm{I}-\mathrm{C} 9$ were prepared in a similar manner as described for ${ }^{125} \mathrm{I}-$ C9-containing pellets, and were also run on $2-12 \%$ gradients.

Elution experiments. Removal of bound ${ }^{125} \mathrm{I}-\mathrm{C} 9$ from the bacterial surface by salt, detergent, or protease was evaluated by a modification of the method of Joiner et al. (7). Bacteria in 20\% PNHS, to which ${ }^{125} \mathrm{I}-\mathrm{C} 9(3.0 \mu \mathrm{g} / \mathrm{ml})$ was added, were incubated for $30 \mathrm{~min}$ as described above, and aliquots were washed twice in veronal-buffered saline containing $0.1 \%$ gelatin, $0.15 \mathrm{mM} \mathrm{CaCl}$, and $0.5 \mathrm{mM} \mathrm{MgCl} 2$ (VBSG++). Pellets were then resuspended and incubated at $37^{\circ} \mathrm{C}$ for $30 \mathrm{~min}$ in $(a)$ VBSG,$++(b) 0.1 \%$ L-1-p-tosylamino-2-phenylethyl chloromethyl ketone (TPCK)-treated trypsin in VBSG ++ (Sigma Chemical Co.), or (c) $1.0 \%$ zwitterionic detergent SB-12 for S. typhimurium strains and in (a) VBSG $++;(b)$ 0.1\% TPCK-treated trypsin in VBSG $++;(c) 1.0 \%$ $\mathrm{Na}$ deoxycholate, $\mathrm{pH} 7.9$; or $(d) 1 \mathrm{M} \mathrm{NaCl}, \mathrm{pH} 7.4$, for $E$. coli 0111 :B4 strains. Samples were centrifuged for $5 \mathrm{~min}$ at $12,500 \mathrm{~g}$, and pellets and supernatants were counted. The amount of ${ }^{125} \mathrm{I}-\mathrm{C} 9$ eluted from the bacterial surface was determined by the percentage of total counts released into the supernatant.

Sucrose density ultracentrifugation. Fractionation of detergent-extracted bacterial outer membranes by sucrose density ultracentrifugation was performed using a modification of the technique of Joiner et al. $(7,39)$. Bacteria were incubated in $20 \%$ PNHS containing ${ }^{125} \mathrm{I}-\mathrm{C} 9$ for $30 \mathrm{~min}$ at $37^{\circ} \mathrm{C}$, washed twice in VBSG ++ , resuspended in $1 \%$
SB- 12 containing $10 \mathrm{mM}$ iodoacetamide, and reincubated for $30 \mathrm{~min}$ at $37^{\circ} \mathrm{C}$. This procedure resulted in extraction of $75.8-82.6 \%$ of bound ${ }^{125} \mathrm{I}-\mathrm{C} 9$ into the supernatant when the mixture was centrifuged at $12,500 \mathrm{~g}$ for $5 \mathrm{~min}$. $10-40 \%$ sucrose density gradients in VBSG++ containing $1 \%$ SB- 12 were prepared in $13 \times 51 \mathrm{~mm}$ polyallomer tubes. The supernatant was applied to the preformed gradient tubes and sedimented in an SW 50.1 rotor (Beckman Instruments, Fullerton, CA) for $15 \mathrm{~h}$ at $39,000 \mathrm{rpm}$ at $4^{\circ} \mathrm{C}$. 10-drop fractions were collected and counted in a gamma counter (Searle Analytic).

Immunoprecipitation. A murine monclonal antibody to SC5b-9 neo-antigen (Quidel, San Diego, CA) was used to immunoprecipitate detergent-extracted bacterial membrane C $5 \mathrm{~b}-9$ complexes ( see above). 40- $\mu \mathrm{l}$ aliquots from sucrose density peak fractions were added to 1,000 $\mu \mathrm{l}$ of anti-SC 5b-9 antibody diluted 1:100 in immunoprecipitation buffer (40) and to $1,000 \mu \mathrm{l}$ of a 1:100 dilution of an unrelated murine monoclonal antibody raised against amebic antigens, which served as a control. To each of these was added $100 \mu \mathrm{l}$ of anti-murine IgG-agarose (Sigma Chemical Co.). The samples were rocked for $16 \mathrm{~h}$ at $4^{\circ} \mathrm{C}$, centrifuged at $12,500 \mathrm{~g}$ for $5 \mathrm{~min}$, and the pellets were washed five times in immunoprecipitation buffer. The pellets and the supernatants from all washes were counted in the gamma counter (Searle Analytic). Specific immunoprecipitation of ${ }^{125} \mathrm{I}-\mathrm{C} 9$ was determined by subtracting the percentage of total counts pelleted by the control monoclonal antibody from the percentage of total counts pelleted by the anti-SC $5 \mathrm{~b}-9$ monoclonal.

Statistical analysis. Data were subjected to statistical analysis by use of the $t$ test (41).

\section{Results}

Effects of pADEO16 on serum resistance of rough and smooth $E$. coli and Salmonella strains. The cosmid construct pADEO16 contains the $r c k$ gene on a $2.1-\mathrm{kb}$ region cloned from the $S$. typhimurium virulence plasmid (18). A site-specific mutation in $r c k$ on pADEO16 abolishes production of the 17-kD Rck outer membrane protein (19); this recombinant construct is designated pK2011. The effects on serum resistance associated with the introduction of pADEO16 and pK2011 into a variety of E. coli and S. typhimurium strains is shown in Table II. The addition of pADEO16 rendered both smooth and rough

Table II. Effect of pADE016 and pK2011 Plasmid Derivatives on Serum Sensitivity of Rough and Smooth E. coli, S. minnesota, and S. typhimurium

\begin{tabular}{llccc}
\hline & & \multicolumn{3}{c}{ Plasmid derivative present } \\
\cline { 4 - 5 } \multicolumn{1}{c}{ Strains } & Experiments & None & pK2011 & pADE016 \\
\hline Smooth & & & & \\
$\quad$ C14028S & 4 & $1.16 \pm 0.43$ & $1.26 \pm 0.20$ & $-0.04 \pm 0.10$ \\
$\quad$ S. minnesota & & & & \\
$\quad$ S218 & 2 & $1.78 \pm 0.25$ & $\mathrm{ND}$ & $-0.07 \pm 0.11$ \\
$\quad$ E. coli $0111: \mathrm{B} 4$ & 3 & $3.77 \pm 0.15$ & $4.34 \pm 0.03$ & $-0.01 \pm 0.16$ \\
Rough & & & & \\
$\quad$ C14028R & 4 & $6.26 \pm 0.38$ & $6.29 \pm 0.48$ & $0.06 \pm 0.18$ \\
S. typhimurium & & & & \\
$\quad$ J42 & 3 & $6.00 \pm 0.98$ & $6.06 \pm 0.66$ & $0.25 \pm 0.33$ \\
$\quad$ E. coli JA221 & 3 & $6.50 \pm 0.13$ & $6.38 \pm 0.30$ & $1.99 \pm 0.53$ \\
S. minnesota Ra & 2 & $6.39 \pm 0.20$ & ND & $2.92 \pm 1.06$ \\
& & & &
\end{tabular}

Values represent the mean $( \pm \mathrm{SD}) \log$ kill of each strain in $50 \%$ PNHS for the indicated number of experiments, as defined in Methods. Negative values indicate growth of strains in PNHS above that seen in the $\mathrm{HI}$ controls. Values for all strains containing pADE016 were significantly different by unpaired $t$ test from corresponding strains without a plasmid derivative or with pK2011. 
bacteria highly resistant to the bactericidal effects of serum. Bacterial survival in 50\% PNHS was comparable to that seen in HI sera for all strains tested, except for the rough strains $E$. coli JA221 and $S$. minnesota $\mathrm{Ra}$, which nevertheless showed a marked increase in survival. Isogenic strains containing construct pK2011 showed serum sensitivity similar to that of the

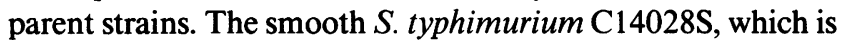
relatively serum resistant due to the presence of long-chain LPS, still displays a significant increase in survival with the introduction of the rck locus. E. coli 0111:B4, which despite its smooth morphology is relatively serum sensitive due to decreased surface coverage with LPS (42), is also rendered fully serum resistant by pADEO16. The introduction of pADEO16 into rough strains caused a marked increase in the serum resistance of the rough, plasmid-cured $S$. typhimurium J42, as shown previously by Hackett et al. (18), and rough, plasmidcured S. typhimurium C14028R. These results indicate that the serum resistance phenotype encoded by $r c k$ is expressed independently of the LPS structure of the host strain.

Rck-induced serum resistance in E. coli 0111:B4 and E. coli 0111:B4 (pADEO16). Having shown that pADEO16 conferred high level serum resistance on rough and smooth $E$. coli and Salmonella strains, we investigated the mechanisms by which this resistance to complement killing was mediated. Preliminary studies were done with strains of $E$. coli 0111 :B4 with and without pADEO16, since the effect of the plasmid was greater in this host than in the other smooth strains tested ( Table II).

Studies of the kinetics of serum killing in 50\% PNHS revealed 1.8 and 2.4 logs of kill of $E$. coli $0111: \mathrm{B} 4$ by 30 and 60 min, respectively (data not shown). In contrast, the introduction of pADEO16 resulted in expression of complete serum resistance at each time point up to $180 \mathrm{~min}$. In addition, we found killing of $E$. coli 0111:B4 (pADEO16) to be negligible at $60 \mathrm{~min}$ in serum concentrations ranging from 2 to $80 \%$ PNHS ( $<0.5$ logs; data not shown $)$.

Since premature fluid-phase activation or destruction of fluid-phase complement components is one of the mechanisms by which bacteria may avoid complement-mediated killing (2), we measured residual complement activity in serum that was incubated with $E$. coli $0111: \mathrm{B} 4$ or $E$. coli $0111: \mathrm{B} 4$ (pADEO16). Both strains depleted serum of complement activity, and both strains reduced total complement activity $(\mathrm{CH} 50)$ at equal rates ( 53.7 and $52.0 \%$ by $30 \mathrm{~min}$, respectively). We also considered that pADEO16 might alter the nature of $\mathrm{C} 3$ binding to the surface of $E$. coli $0111: \mathrm{B} 4$ (pADEO16) or enhance C3 degradation. The relative amounts of $\mathrm{C} 3 \mathrm{~b}$ and $\mathrm{iC} 3 \mathrm{~b}$ bound to both strains were evaluated by SDS-PAGE and found to be similar. In addition, methylamine treatment of these pellets led to the release of equivalent amounts of $\mathrm{C} 3 \mathrm{~b}$, indicating that similar amounts of $\mathrm{C} 3 \mathrm{~b}$ were bound by ester bonds to the surfaces of both strains (data not shown). We also determined that the amount and kinetics of $\mathrm{C} 3$ binding to the two strains over $60 \mathrm{~min}$ is similar.

Since we found no differences in the amount of $\mathrm{C} 3$ bound or in the activation of surface-bound $\mathrm{C} 3 \mathrm{~b}$, we hypothesized that $r c k$ either prevents formation of the complete terminal C5b-9 MAC or renders it nonlytic. We studied C9 binding as a means of determining whether C5b-9 was formed on the bacterial surface. Since $C 9$ is known to be deposited only in the presence of C5b-8 (43), C9 binding would be indirect evidence that the complement cascade had progressed to the terminal membrane complex C5b-9. We detected binding of radiolabeled $\mathrm{C} 9$ to both $E$. coli $0111: \mathrm{B} 4$ and $E$. coli $0111: \mathrm{B} 4$ (pADEO16), with a progressive increase in cell-associated $C 9$ over a 30-min incubation period; binding to $E$. coli 0111:B4 (pADEO16) was slightly less than to $E$. coli 0111 :B4 after $15 \mathrm{~min}$ (data not shown).

To test the nature of this $\mathrm{C} 9$ binding, the cell-associated ${ }^{125} \mathrm{I}-\mathrm{C} 9$ was eluted by a salt solution, detergent, or protease (Table III). There was no significant difference between the amount of radiolabeled $\mathrm{C} 9$ eluted from the surfaces of the two strains by either $\mathrm{VBSG}++, 1 \mathrm{M} \mathrm{NaCl}$, or $1 \% \mathrm{Na}$ sodium deoxycholate. However, C9 on E. coli 0111:B4 (pADEO16) was significantly more susceptible to proteolytic release by $0.1 \%$ tryp$\sin$. Elution by trypsin resulted in release of $48.9 \%$ of radiolabeled $\mathrm{C} 9$ from the surfaces of complement-sensitive $E$. coli 0111:B4. In contrast, $74.6 \%$ of ${ }^{125} \mathrm{I}-\mathrm{C} 9$ was eluted from complement-resistant $E$. coli 0111:B4 (pADEO16) $(P=0.005)$. Based on these preliminary studies, we initially hypothesized that the C5b-9 complex is present on cells expressing $r c k$, but that the polymerization or binding of $\mathrm{C} 9$ is different, such that the MAC does not insert effectively in the hydrophobic regions of the outer membrane, as it does in serum-sensitive $E$. coli 0111:B4.

Time-kill curves in 50\% PNHS of smooth and rough $S$. typhimurium 14028 containing pADEO16 and pK2011. The above studies in E. coli 0111:B4 (pADEO16) suggest that the $r c k$-induced effect on complement sensitivity probably acts at the level of the terminal Cb5-9 membrane attack complex. Further studies were performed using smooth $S$. typhimurium 14028 S and rough $S$. typhimurium 14028R cured of the virulence plasmid (C14028S and C14028R), in order to place the $r c k$ gene in the native host and to eliminate the possible confounding effects of the native virulence plasmid $r c k$ gene. The cosmid constructs pADEO16 and pK2011 were mated into C14028S and C14028R; the use of pK2011 insured that differences between pADEO16- and pK2011-containing strains should be attributable solely to the presence or absence of the rck gene product.

In both C14028S and C14028R, as shown in Table II, the addition of pADE016 conferred complete resistance to $50 \%$ PNHS, whereas pK2011 had no discernable effect. The kinetics of this resistance is shown in Fig. 1. C14028R(pK2011) is rapidly killed, with four logs of kill in $10 \mathrm{~min}$; C14028S(pK2011) is relatively serum resistant but still shows slightly over one log of kill in $30 \mathrm{~min}$. In contrast, there was no killing of C14028S(pADEO16) or C14028R(pADEO16).

$C 5$ binding to smooth and rough $S$. typhimurium $C 14028$ containing pADEO16 and pK2011. C5 binding to C14028S-

Table III. Release of ${ }^{125} I-C 9$ from E. coli 0111:B4 and E. coli 0111:B4 (pADE016) by VBSG++, $\mathrm{NaCl}, \mathrm{NaDOC}$, and Trypsin

\begin{tabular}{llcr}
\hline \multirow{2}{*}{$\begin{array}{c}\text { Elution } \\
\text { conditions }\end{array}$} & \multicolumn{3}{c}{ Percentage of pellet counts released into supernatant } \\
\cline { 2 - 4 } & $\begin{array}{c}E . \text { coli } \\
0111: \mathrm{B} 4\end{array}$ & $\begin{array}{c}E . \text { coli } \\
\text { 0111:B4(pADE016) }\end{array}$ & $P$ value \\
\hline VBSG++ & $44.8 \pm 14.6$ & $48.9 \pm 6.8$ & 0.513 \\
$1 \mathrm{M} \mathrm{NaCl}$ & $71.0 \pm 12.7$ & $69.7 \pm 5.4$ & 0.805 \\
$1 \% \mathrm{NaDOC}$ & $83.2 \pm 7.6$ & $77.9 \pm 14.7$ & 0.416 \\
$0.1 \%$ Trypsin & $48.9 \pm 17.3$ & $74.6 \pm 9.1$ & 0.005
\end{tabular}

Each value represents the mean $\pm \mathrm{SD}$ of six experiments. 


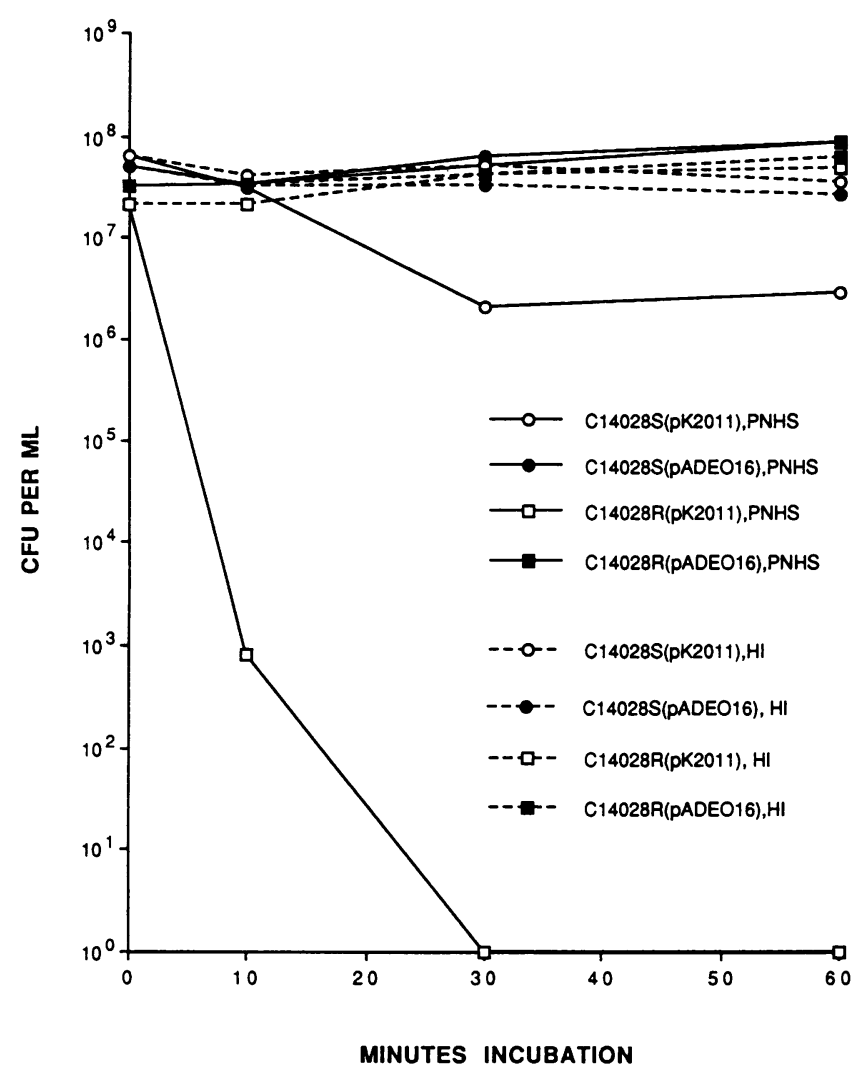

Figure 1. Time-kill curve of $S$. typhimurium 14028 strains containing either pADEO16 or pK2011. Comparable suspensions of mid-log phase bacteria $\left(\sim 5 \times 10^{7} / \mathrm{ml}\right)$ were incubated at $37^{\circ} \mathrm{C}$ in $50 \%$ PNHS or HI. Aliquots were removed at $0,15,30$, and $60 \mathrm{~min}$ and were plated for viability counts. Viability of surviving bacteria are expressed as the log base 10 of the colony counts.

(pADEO16), C14028S(pK2011), C14028R(pADEO16), and C14028R (pK2011) is shown in Fig. $2 A$. There are no significant differences in $\mathrm{C} 5$ binding between any of the strains at either 10,30 , or $60 \mathrm{~min}$, and the kinetics of binding are similar. We repeated these experiments in $20 \%$ PNHSand C8-depleted sera, using C14028R(pADEO16) and C14028R(pK2011). There are no significant differences in the binding of $\mathrm{C} 5$ in $20 \%$ PNHS- or C8-depleted sera in these strains (Fig. $2 \mathrm{~B}$ ), indicating that bacteriolysis of the serumsensitive strains does not significantly affect the results of the binding assay. It appears that $\mathrm{C} 5$, the initial component of the terminal MAC, binds equally well to strains with and without $r c k$.

C9 binding to smooth and rough S. typhimurium C14028 containing pADEO16 and $p K 2011$. C9 binding to smooth C14028S (pADEO16) and C14028S (pK2011) is shown in Fig. $3 \mathrm{~A}$. At all three time points there is less $\mathrm{C} 9$ binding to the rck-containing strain C14028S(pADEO16), (35.1, 69.9, and $70.0 \%$ of the mean C9 binding to $\mathrm{C} 14028 \mathrm{~S}$ (pK2011) at 10,30, and $60 \mathrm{~min}$, respectively); these differences reach statistical significance at $30 \mathrm{~min}(P=0.015)$, and nearly so at $60 \mathrm{~min}(P$ $=0.057$ ).

We find that all our rough $S$. typhimurium strains tested, (including $S$. typhimurium $14028 \mathrm{R}$ and $S$. typhimurium C14028R; data not shown), bind two to nine times more C9 than the smooth strains. Similar findings were noted by Joiner et al. in their studies of rough and smooth $S$. minnesota (6) and
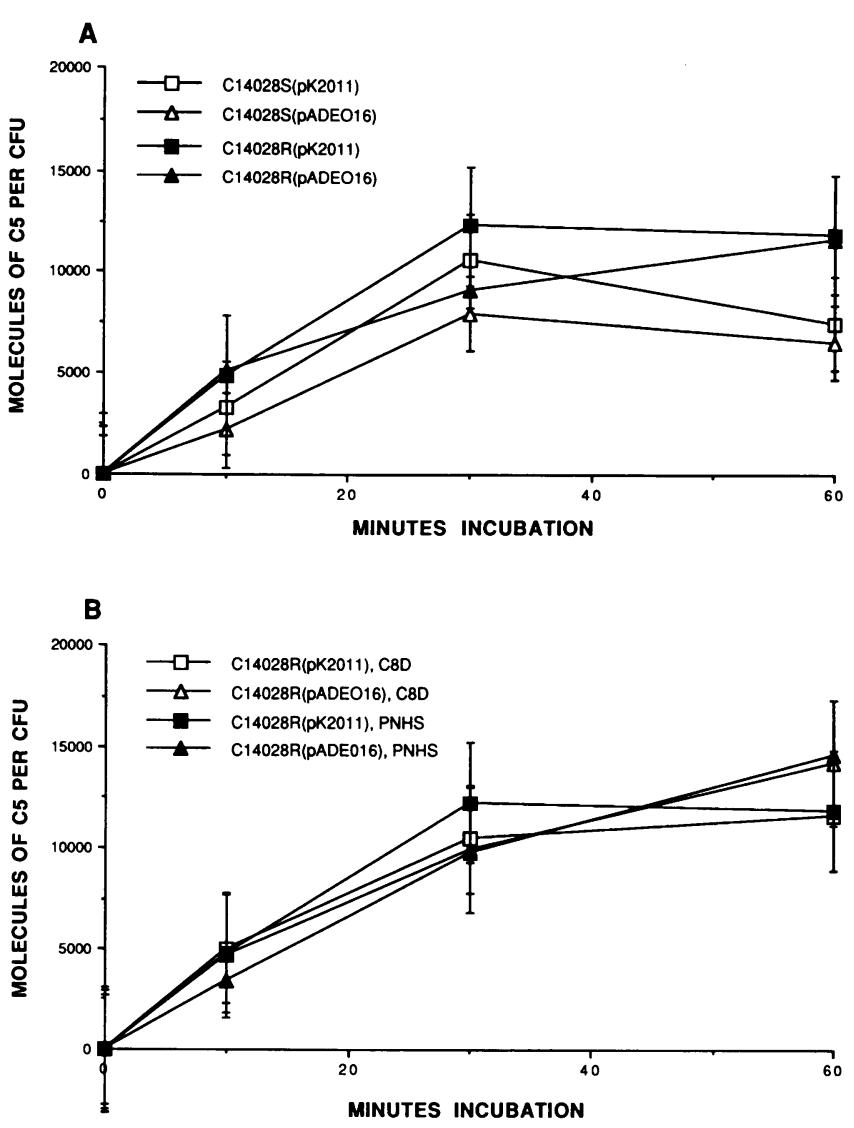

Figure 2. C5 binding to $S$. typhimurium $\mathrm{C} 14028$ strains containing either pK2011 or pADEO16. Bacteria $\left(2 \times 10^{8} / \mathrm{ml}\right)$ were incubated in $20 \%$ sera at $37^{\circ} \mathrm{C}$ to which ${ }^{125} \mathrm{I}-\mathrm{C} 5$ was added. Aliquots were removed at timed intervals, pellets separated by centrifugation, and bound counts determined. Molecules of $\mathrm{C} 5$ specifically bound per CFU were calculated by subtracting counts bound in HI sera from counts bound in PNHS or C8D and correcting for the specific activity of the labeled component, the ratio of the labeled to the unlabeled component, and CFUs/ml. Values represent the mean of four experiments plus or minus the standard error. $(A)$ Specific $\mathrm{C} 5$ binding to $\mathrm{C} 14028 \mathrm{~S}$ and $\mathrm{C} 14028 \mathrm{R}$ strains containing either pK2011 or pADE016) in PNHS. $(B)$ Specific C5 binding to C14028R strains containing either pK2011 or pADEO16 in C8D and in PNHS.

S. typhimurium (44). C9 binding to rough strains C14028R(pADEO16) and C14028R(pK2011) is shown in Fig. $3 B$. As with the smooth strains, we found that there is less C9 binding to the rough $r c k$-containing strain $\mathrm{C} 14028 \mathrm{R}$ (pADEO16) at all time points, $(57.7,49.1$, and $65.8 \%$ of the mean C9 binding to $S$. typhimurium C14028R[pK2011] at 10, 30, and $60 \mathrm{~min}$, respectively); the differences reach statistical significance at $30 \mathrm{~min}(P=0.01)$, and nearly so at $60 \mathrm{~min}(P$ $=0.067$ ). Similar differences are seen at 90 and $120 \mathrm{~min}$ (data not shown).

SDS-PAGE of ${ }^{125}$ I-C9-labeled rough and smooth S. typhimurium containing pADEO16 and pK2011. Although S. typhimurium strains containing $r c k$ stably bind less $C 9$ than do isogenic strains without $r c k$, it seemed unlikely to us that these modest differences alone could account for the marked increases in serum resistance associated with the presence of $r c k$. There is a marked difference between the survival of rough $r c k$ strains and rough strains without $r c k$ by $10 \mathrm{~min}$ ( $>4$ logs; Fig. 1) before large absolute differences in C9 binding are apparent 

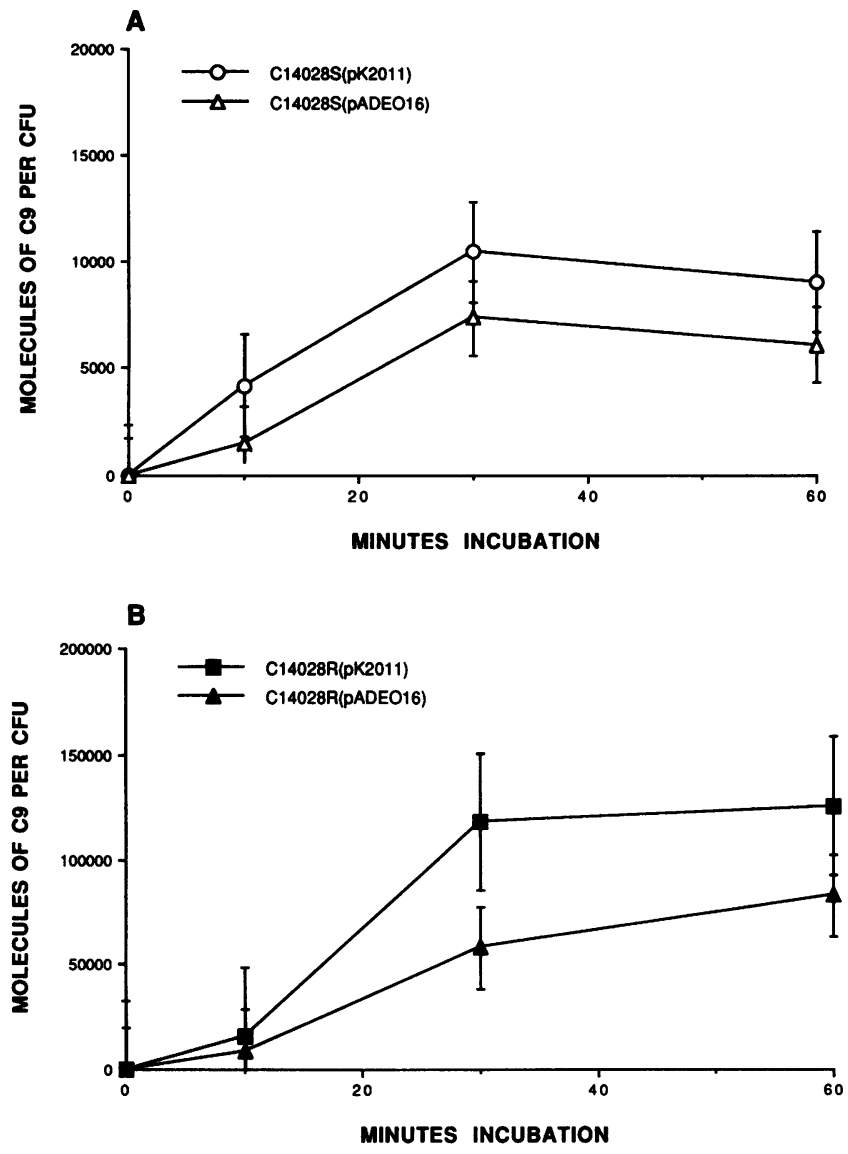

Figure 3. C9 binding to $S$. typhimurium $\mathrm{C} 14028$ strains containing either pK2011 or pADEO16. Bacteria $\left(2 \times 10^{8} / \mathrm{ml}\right)$ were incubated in $20 \%$ sera at $37^{\circ} \mathrm{C}$ to which ${ }^{125} \mathrm{I}-\mathrm{C} 9$ was added. Aliquots were removed at timed intervals, pellets separated by centrifugation, and bound counts determined. Molecules of C 9 specifically bound per CFU were calculated by subtracting counts bound in HI sera from counts bound in PNHS and correcting for the specific activity of the labeled component, the ratio of the labeled to the unlabeled component, and CFUs/ml. Values represent the mean of six experiments plus or minus the standard error. $(A)$ Specific $C 9$ binding to $C 14028 \mathrm{~S}$ containing either pK2011 or pADEO16. $(B)$ Specific C9 binding to C14028R containing either pK2011 or pADEO16. Note that the scale for $B$ is one $\log$ greater than that for $A$.

(Fig. $3 \mathrm{~B}$ ). In addition, $\mathrm{C} 9$ binding to rough $\mathrm{C} 14028 \mathrm{R}$ (pADEO16), although less than with rough $S$. typhimurium $\mathrm{C} 14028 \mathrm{R}$ (pK2011), is more than 2.5 times greater at all time points than that seen with smooth C14028S(pK2011); despite this, $\mathrm{C} 14028 \mathrm{~S}$ ( $\mathrm{pK} 2011$ ) is killed in 50\% PNHS, whereas rough C14028R (pADEO16), containing $r c k$, is not (Table II).

We hypothesized that the decrease in $\mathrm{C} 9$ binding mediated by $r c k$ might be due to either complete or partial inhibition of C9 polymerization in the C5b-9 complex. To determine whether $\mathrm{C} 9$ bound to $S$. typhimurium bacterial membranes formed high molecular weight complexes consistent with tubular MACs, the molecular form of C9 bound to C14028S(pADEO16), C14028S(pK2011), C14028R(pADEO16), and C14028R(pK2011) was determined as described in Methods. Complete absence of high molecular weight $\mathrm{C} 9$ on the surface of the $r c k$-containing strains would suggest that $C 9$ is not polymerized into the tubular form of the MAC known to be resis- tant to SDS (45). Evaluation of the pellets by SDS-PAGE (2$12 \%$ gradient gel) under reducing conditions showed that $C 9$ formed high molecular weight, SDS-resistant polymeric complexes on all strains (Fig. 4). This result indicates that the decrease in C9 binding seen in C14028S (pADEO16) and C14028R(pADEO16) does not result in complete absence of SDS-resistant polymerized C9 on the bacterial surface. Nevertheless, although all strains show evidence of high molecular weight C9 complexes, there appears to be relatively fewer of these complexes associated with the $r c k$-containing strains C14028S(pADEO16) and C14028R(pADEO16).

Elution studies. We speculated that $r c k$-mediated serum resistance might be associated with a relative shift away from SDS-resistant polyC9; alternatively, since $r c k$ does not completely inhibit the formation of SDS-resistant polymeric C9 on the bacterial surface, it may act by directly preventing insertion of polymeric $\mathrm{C} 9$ into the hydrophobic regions of the bacterial outer membrane, a stage known to be necessary for complement-mediated killing in serum-sensitive bacteria (44-46). Both SDS-sensitive polymeric C9 and C5b-9 complexes not fully inserted in the outer membrane have been shown to be sensitive to trypsin proteolysis $(7,47,48)$. Based on our initial studies with $E$. coli $0111: \mathrm{B} 4$, we chose to test these possibilities by examining the $\mathrm{C} 9$ eluted from the bacterial surface using a salt solution, detergent, or protease. There is no significant difference between the percentage of radiolabeled $\mathrm{C} 9$ eluted from the surfaces of smooth strains with and without $r c k$ by either VBSG++ or the zwitterionic detergent SB-12 (Table IV). Elution with VBSG++ and SB-12 results in slightly greater release of C9 from C14028R(pADEO16) than from S. typhimurium C14028R(pK2011), although only with VBSG++ were these differences significant. Comparison of proteolytic release of $\mathrm{C} 9$ by $0.1 \%$ trypsin showed more marked differences. Relatively little C9 is eluted from the surface of C14028R(pK2011) (26.4\%). In contrast, $55.7 \%$ of ${ }^{125} \mathrm{I}$-C9 was eluted from C14028R(pADEO16) by trypsin treatment $(P=0.005)$; the differences were similar to those seen between $E$. coli 0111:B4 and $E$. coli 0111:B4 pADEO16 (Table III). Smaller differences

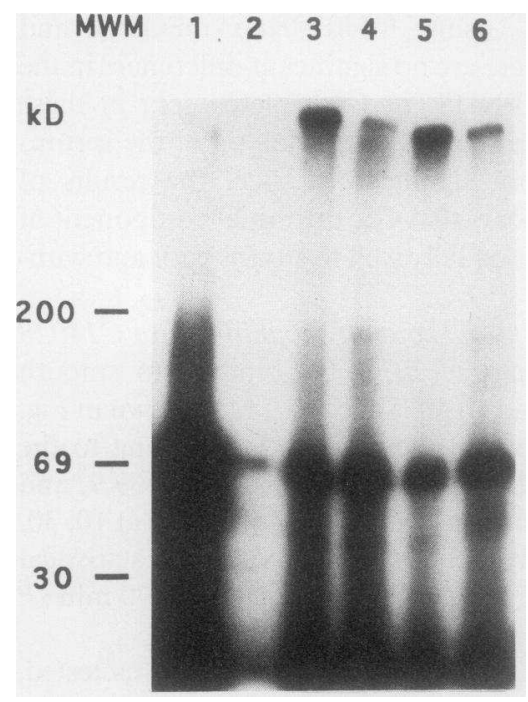

Figure 4. Molecular form of ${ }^{125} \mathrm{I}-\mathrm{C} 9$ bound to $S$. typhimurium C14028 strains containing pADEO 16 or pK2011. Bacteria were incubated for $1 \mathrm{~h}$ with ${ }^{125}$ I-labeled C9 in $20 \%$ PNHS at $37^{\circ} \mathrm{C}$; supernatants and pellets were electrophoresed by SDS-PAGE (2-12\%) under reducing conditions. All sample lanes were loaded with 10,000 cpm. Lane 1, polyC9 neoantigen; lane 2 , monomeric $\mathrm{C} 9$; lane 3, $\mathrm{C} 14028 \mathrm{R}(\mathrm{pK} 2011)$; lane 4, C14028R(pADEO16); lane 5 ,

C14028S(pK2011); lane 6 C14028S(pADEO16). Note that only small amounts of the high molecular weight polyC 9 neoantigen control are visible in lane $l$ under these conditions. 
Table IV. Release of ${ }^{125}$ I-C9 from C14028S (pK2011), C14028S (pADE016), C14028R (pK2011), and C14028R (pADE016) by $V B S G++$, Trypsin, and $S B-12$

\begin{tabular}{|c|c|c|c|c|c|c|}
\hline \multirow{2}{*}{$\begin{array}{l}\text { Elution } \\
\text { conditions }\end{array}$} & \multicolumn{3}{|c|}{ C14028S } & \multicolumn{3}{|c|}{$\mathrm{C} 14028 \mathrm{R}$} \\
\hline & K2011 & pADE016 & $P$ value & K2011 & pADE016 & $P$ value \\
\hline VBSG ++ & $41.2 \pm 5.7$ & $42.9 \pm 11.5$ & 0.648 & $13.2 \pm 5.4$ & $23.0 \pm 4.2$ & 0.006 \\
\hline Trypsin & $70.5 \pm 15.4$ & $81.6 \pm 6.0$ & 0.060 & $26.4 \pm 8.2$ & $55.7 \pm 8.2$ & 0.001 \\
\hline SB-12 & $76.4 \pm 9.7$ & $81.0 \pm 5.7$ & 0.392 & $75.8 \pm 4.1$ & $82.6 \pm 8.8$ & 0.438 \\
\hline
\end{tabular}

Values for VBSG ++ and Trypsin elutions represent the mean \pm SD of six experiments; those for SB-12 elutions represent the mean of three experiments. $P$ values were calculated by means of Student's paired $t$ test.

between C14028S(pADEO16) and C14028S(pK2011) in trypsin release of $\mathrm{C} 9$ approached but did not reach significance $(P=0.06)$. The percentages of $C 9$ eluted by any method was consistently higher in the smooth strains than in the rough strains; Joiner et al. $(6,7)$ showed that in smooth $S$. minnesota most $C 9$ is deposited on long-chain LPS at a distance from the outer membrane. This peripherally bound C 9 tends to release spontaneously from the bacterial surface and is more susceptible to elution by both salt and proteases than is $\mathrm{C} 9$ deposited on rough strains. These experiments indicated that $\mathrm{C} 9$ on the surface of $r c k$-containing bacteria may be less tightly bound than that on bacteria without $r c k$ and may be more susceptible to proteolytic cleavage, confirming the initial findings in $E$. coli 0111:B4.

Sucrose density gradient analysis. To determine if there were differences in the size and form of the high molecular weight $\mathrm{C} 9$ complexes bound to the surfaces of strains with and without $r c k$, we subjected detergent-extracted ${ }^{125}$ I-C9-labeled bacterial membranes from C14028R(pADEO16) and $\mathrm{C} 14028 \mathrm{R}$ (pK2011) to sucrose density gradient ultracentrifugation. Joiner et al. (48) showed previously that terminal C5b-9 complexes, inserted in serum-sensitive Neisseria gonorrhoeae outer membranes, sedimented predominantly as a single sharp high molecular weight peak at $\sim 33 \mathrm{~S}$, with a small shoulder at 23S. We found that ${ }^{125} \mathrm{I}-\mathrm{C} 9$ extracted from C14028R(pK2011) had a very similar sedimentation profile (Fig. $5 A$ ), with a single prominent high molecular weight peak (peak $A$ ) with a small shoulder (peak B). However, ${ }^{125} \mathrm{I}-\mathrm{C} 9$ extracted from serum-resistant C14028R(pADEO16) shows a markedly different profile. In addition to the smaller high molecular weight peak (a) corresponding to peak A, there is a second and more prominent peak (b) running higher in the gradient, indicating the presence of large amounts of ${ }^{125} \mathrm{I}-\mathrm{C} 9$ associated with somewhat lower molecular weight complexes. In addition, there appears to be more low molecular weight $\mathrm{C} 9$, running in the range of monomeric $\mathrm{C} 9$, in the $\mathrm{C} 14028 \mathrm{R}$ (pADEO16) gradients.

Similar findings were noted in sucrose density gradient ultracentrifugation studies with ${ }^{125} \mathrm{I}$-C9-labeled smooth C14028S(pADEO16) and C14028S (pK2011) (Fig. 5 B). Distribution of membrane-extracted C9 in the sensitive strain $S$. typhimurium C14028S(pK2011) is similar to that previously described in smooth $S$. minnesota (7): a broader high molecular weight peak (peak M) with a lower molecular weight shoulder (N). The rck-containing strain, $S$. typhimurium C14028S (pADEO16), shows a shift in C9 from the higher molecular weight region (peak $\mathrm{m}$ ) to the lower molecular weight peak ( peak $n$ ).
To determine whether these differences in distribution of extracted C9 reflected differences in the entire C5b-9 complex, sucrose density gradient ultracentrifugation studies were undertaken using ${ }^{125} \mathrm{I}-\mathrm{C} 5-$ labeled $S$. typhimurium C14028R(pADEO16) and $S$. typhimurium C14028R(pK2011) (Fig. 5 C). The gradient curves were different than those seen with membrane-extracted $\mathrm{C} 9$, with most $\mathrm{C} 5$ in both strains running as a low molecular weight species consistent with monomeric $\mathrm{C} 5$ (peaks Z, z). Similar C5 curves have been reported previously, suggesting that significant amounts of $\mathrm{C} 5$ bound to the bacterial surface do not participate in C5b-9 complexes (49). The smaller, high molecular weight regions $\mathrm{X}, \mathrm{x}$ and $\mathrm{Y}, \mathrm{y}$ appear to correspond to peaks A, a and B, b of Fig. $5 A$ and peaks M, m and $\mathrm{N}$, $\mathrm{n}$ of Figure $5 B$, indicating that both $\mathrm{C} 5$ and $\mathrm{C} 9$ are present in these high molecular weight regions. The only significant difference between the $\mathrm{C} 5$ sedimentation profiles of the two strains was the small high molecular weight peak $(X)$ in C14028R(pK2011) not present in C14028R(pADEO16).

Immunoprecipitation of sucrose density gradient peaks with monoclonal antibodies raised against SC5b-9. To determine whether the high molecular weight peaks in the ${ }^{125} \mathrm{I}-\mathrm{C} 9$ sucrose density gradients represented polymeric or monomeric $\mathrm{C}$, we immunoprecipitated the ${ }^{125} \mathrm{I}-\mathrm{C} 9$ in the peak fractions of C14028R (pADEO16) and C14028R (pK2011) by use of a murine monoclonal antibody raised against the fluid-phase SC5b9 complex. This antibody reacts with polymerized C9 and not with monomeric C9 on immunoblots (data not shown); in addition, it specifically immunoprecipitates more polymerized C9 neoantigen than monomeric C9 (38 vs. 16\%). Most of the ${ }^{125} \mathrm{I}$-C9 associated with the highest molecular weight peaks (A, a) is specifically immunoprecipitated by the anti-SC $5 \mathrm{~b}-9$ antibody ( 56.5 and $70.8 \%$, respectively), as shown in Table V. The ${ }^{125} \mathrm{I}-\mathrm{C} 9$ associated with peaks $\mathrm{B}$ and $\mathrm{b}$ is also immunoprecipitated by this antibody, although to a lesser extent ( 34.2 and $58.3 \%$, respectively). The percentage of monomeric-range ${ }^{125} \mathrm{I}$ C9 immunoprecipitated (peaks $\mathrm{C}$ and $\mathrm{c}$ ) is significantly less than the percentage immunoprecipitated from peaks A, a, B, and $b$.

The higher molecular weight regions $(\mathrm{X}, \mathrm{x}, \mathrm{Y}, \mathrm{y})$ in the $\mathrm{C} 5$ gradients from both C14028R(pADEO16) and C14028R(pK2011) were also specifically immunoprecipitable by the anti-SC5b-9 monoclonal antibody, whereas the large low molecular weight peaks showed no immunoprecipitation (data not shown). This suggests that ${ }^{125} \mathrm{I}-\mathrm{C} 5$ in fraction peaks $\mathrm{X}, \mathrm{x}, \mathrm{Y}$, and $y$ also exists as high molecular weight complexes recognizable to the anti-SC5b-9 monoclonal antibody, most likely in the form of $\mathrm{C} 5 \mathrm{~b}-9$, since this antibody also immunoprecipitates ${ }^{125} \mathrm{I}-\mathrm{C} 9$ from comigrating peaks. 

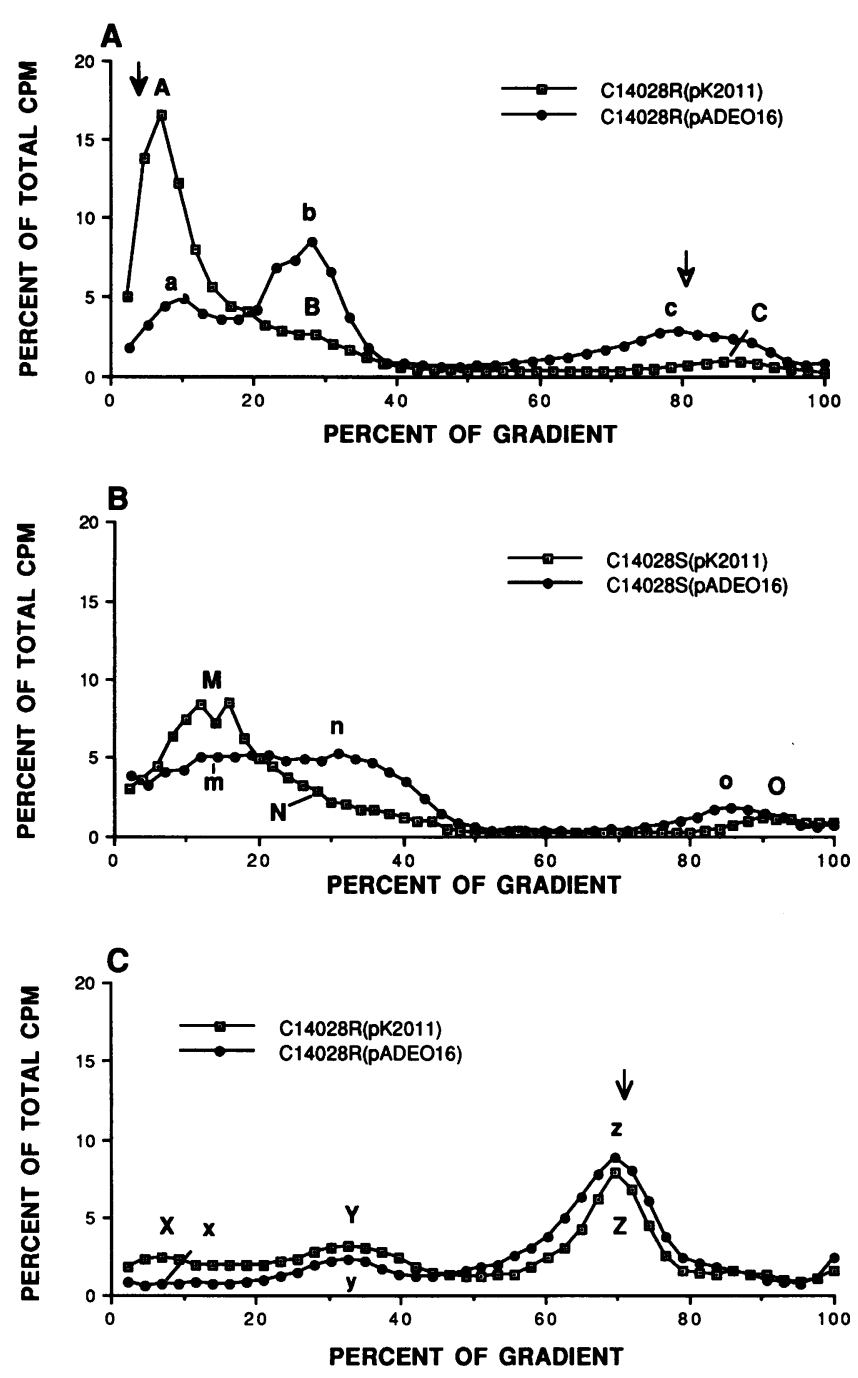

Figure 5. Sucrose density gradient ultracentrifugation of detergentextracted ${ }^{125} \mathrm{I}-\mathrm{C} 9$ or ${ }^{125} \mathrm{I}-\mathrm{C} 5$ from smooth and rough $S$. typhimurium with and without $r c k$. Bacteria were incubated in $20 \%$ PNHS containing ${ }^{125} \mathrm{I}-\mathrm{C} 9$ or ${ }^{125} \mathrm{I}-\mathrm{C} 5$ for $30 \mathrm{~min}$ at $37^{\circ} \mathrm{C}$, washed twice, resuspended in $1 \% \mathrm{SB}-12$, and reincubated for $30 \mathrm{~min}$ at $37^{\circ} \mathrm{C}$. The supernatant was applied to preformed $10-40 \%$ sucrose density gradients and sedimented for $15 \mathrm{~h}$ at $39,000 \mathrm{rpm}$ at $4^{\circ} \mathrm{C}$. 10-drop fractions were collected and counted. $(A){ }^{125} \mathrm{I}-\mathrm{C} 9$ extracted from C14028R(pADEO16) and C14028R(pK2011) (B) ${ }^{125} \mathrm{I}-\mathrm{C} 9$ extracted from C14028S (pADEO16) and C14028S(pK2011) $(C)^{125} \mathrm{I}-\mathrm{C} 5 \mathrm{ex}-$ tracted from C14028R(pADEO16) and C14028R(pK2011). Fraction cpm and number are normalized to percent of total cpm and number, respectively. The figures shown are representative curves of six $(A)$ or three $(B$ and $C)$ experiments.

SDS-PAGE autoradiography of sucrose density gradient ultracentrifugation peak fractions. It appeared likely that the higher molecular weight peaks and shoulders in both C14028R (pADEO16) and C14028R (pK2011) contain C5b-9 complexes. To investigate whether these complexes contain SDS-resistant polymeric $\mathrm{C} 9$, as is present in the tubular MAC (47), we subjected fraction peaks A, a, B, and b to SDS-PAGE autoradiography (Fig. 6). The fractions from the predominant peak (A) of C14028R(pK2011) showed the presence of high molecular weight complexes containing ${ }^{125} \mathrm{I}-\mathrm{C} 9$, as did the corresponding but smaller high molecular weight peak (a) of
Table V. Specific Immunoprecipitation of ${ }^{125}$ I-C 9 from Peak Sucrose Density Gradient Fractions by anti-SC5b-9 Monoclonal Antibody

\begin{tabular}{cccc}
\hline & \multicolumn{3}{c}{$\begin{array}{c}\text { Percent of }{ }^{125} \text { I-C9 immunoprecipitated from } \\
\text { specified peak fractions }\end{array}$} \\
\cline { 2 - 4 } Strain & $\mathrm{A}$ & $\mathrm{B}$ & $\mathrm{C}$ \\
\hline $\mathrm{C} 14028 \mathrm{R}(\mathrm{pK} 2011)$ & $56.5 \pm 19.6$ & $34.2 \pm 12.4$ & $12.5 \pm 8.8$ \\
& $\mathrm{a}$ & $\mathrm{b}$ & $\mathrm{c}$ \\
\hline C14028R(pADE016) & $70.8 \pm 2.1$ & $58.3 \pm 17.2$ & $9.8 \pm 3.7$
\end{tabular}

Each value represents the mean \pm SD of three experiments. A, B, C and $\mathrm{a}, \mathrm{b}, \mathrm{c}$ refer to sucrose density gradient peak fractions as shown in Fig. $5 \mathrm{~A}$.

C14028R(pADEO16). However, there was only a faint high molecular weight band from shoulder (B) of $S$. typhimurium C14028R(pK2011), and no polymeric C9 was detected from peak (b) of C14028R(pADEO16). Similar results were obtained with peaks $M$ and $N$ of $C 14028 \mathrm{~S}$ (pK2011) and peaks $\mathrm{m}$ and $n$ of C14028S(pADEO16) (data not shown).

The single major peak seen with C14028R (pK2011) (peak A, Fig. $5 A$ ) most likely represents terminal C5b-9 complexes containing multiple molecules of $\mathrm{C} 9$, since at least three molecules of $C 9$ are necessary for formation of SDS-resistant tubular polyC9 (50). High molecular weight MACs are generally heterogenous, containing both SDS-resistant tubular polyC 9 and linear $\mathrm{C} 9$ that is broken down to monomeric $\mathrm{C} 9$ by SDS under reducing conditions (49); both populations are seen in the SDS-PAGE of peak A (Fig. 6, lane 1). The corresponding but smaller peak in $S$. typhimurium C14028R(pADEO16) (Fig. $5 \mathrm{~A}$, peak a) most likely also contains some intact high molecular weight, tubular MAC. However, the slower sedimenting peak seen uniquely in the $r c k$-containing strain (Fig. 5 $A$, peak b) appears to represent $\mathrm{C} 5 \mathrm{~b}-9$ complexes that, al-

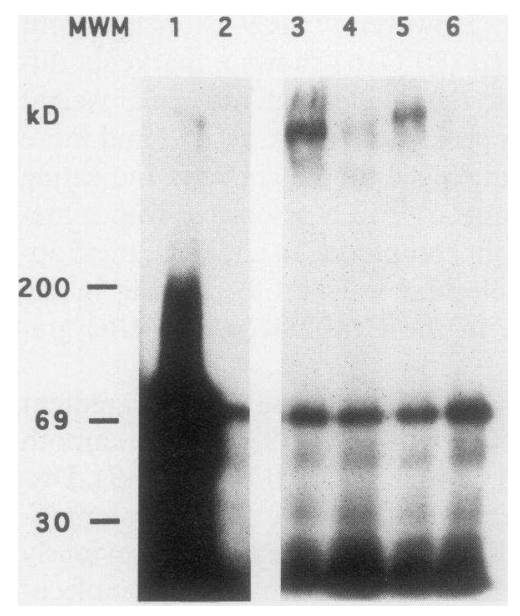

Figure 6. Molecular form of ${ }^{125} \mathrm{I}-\mathrm{C} 9$ in peak fractions from sucrose density gradient ultracentrifugations of $S$. $t y$ phimurium C14028R containing pADEO16 or K2011. Aliquots from peak and shoulder fractions $A$ and $B$ [C14028R(K2011)] and from peak fractions

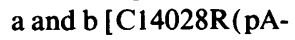
DEO16)] from Fig. 5 were electrophoresed by SDS-PAGE (2-12\%) under reducing conditions. All sample lanes were loaded with 1,000 cpm. Lane 1, polyC9 neoantigen; lane 2, monomeric C9; lane 3, peak A; lane 4, shoulder B; lane 5 , peak a; lane 6 , peak b. Note that only small amounts of the high molecular weight polyC 9 neoantigen control are visible in lane $l$ under these conditions. 
though recognized by the anti-SC $5 b-9$ monoclonal antibody, do not contain SDS-resistant, polymeric C9 indicative of the tubular MAC.

\section{Discussion}

We have previously shown that the $S$. typhimurium virulence plasmid $r c k$ gene, encoding a $17-\mathrm{kD}$ outer membrane protein product Rck, is responsible for serum resistance induced in S. typhimurium $\mathrm{J} 42$ by introduction of recombinant cosmid pADEO16 (19). In the present study we showed that pADEO16 conferred upon a variety of rough and smooth $E$. coli and Salmonella serotypes the ability to grow in 50\% PNHS at rates comparable to their growth in HI serum controls. This effect was abolished when we made a deletion mutation in the $r c k$ gene. These studies confirm and extend the original observations made by Hackett et al. (18) that a segment of the virulence plasmid could mediate serum resistance in rough $E$. coli and $S$. typhimurium strains without restoring or altering the LPS electrophoretic profile (18).

Because pADEO16 had such a profound effect on serum resistance (increasing survival by over six logs), we decided to determine how $r c k$ subverts the bactericidal effect of complement. Preliminary studies were performed using $E$. coli 0111:B4 and E. coli 0111:B4 pADEO16. We found no significant difference in the activation or depletion of fluid-phase complement components, in C 3 binding, in the percentage of $\mathrm{C} 3$ bound to the bacteria by thio-ester bonds, or in the amount of $\mathrm{C} 3$ that was degraded to $\mathrm{C} 3 \mathrm{~b}$ and $\mathrm{iC} 3 \mathrm{~b}$. Furthermore, $\mathrm{C} 9$ binding to $E$. coli 0111 and $E$. coli 0111 :pADEO16 was not significantly different. Since C 9 binds only as part of the C5b-9 terminal membrane complex, this implied that C5 convertases were not affected by $r c k$, and that the terminal membrane complex formed on the surface. However, we found that $\mathrm{C} 9$ bound to $E$. coli 0111 :pADEO16 was more susceptible to proteolytic cleavage by trypsin than was $C 9$ bound to $E$. coli 0111 . These results led us to hypothesize that $r c k$ affected the interaction between the C5b-9 membrane attack complex and the outer membrane of the bacteria.

We tested our hypothesis by introducing pADEO16 or pK2011 (containing a knockout mutation in $r c k$ ) into smooth and rough $S$. typhimurium 14028 strains cured of the native virulence plasmid. C5 bound equally to all of these strains, confirming that $r c k$ did not inhibit the activity of C5 convertases. We did find that less C9 was bound by $S$. typhimurium 14028 strains expressing $r c k$, although these differences were significant only after $30 \mathrm{~min}$ of incubation. These differences in $C 9$ binding are unlikely to account for the $r c k$-induced effect on serum resistance, however. In kinetic experiments we found that after $10 \mathrm{~min}$ there was no significant difference in the amount of $\mathrm{C} 9$ bound by rough $S$. typhimurium with and without $r c k$, whereas there was already a four log difference in serum killing between the two $S$. typhimurium strains (Fig. 1). Furthermore, the total amount of $\mathrm{C} 9$ bound does not appear to correlate with serum killing since rough $S$. typhimurium expressing $r c k$ binds two to nine times more $\mathrm{C} 9$ than the smooth $S$. typhimurium without $r c k$, yet the latter is killed in $50 \%$ PNHS and the former is not.

However, the nature of bound C9 does appear to correlate with serum susceptibility in these strains. C9 bound to rough $S$. typhimurium with $r c k$ was more susceptible to proteolytic release by trypsin and, to a lesser extent, to elution by VBSG ++ .
It is known that failure of C5b-9 complexes to insert deeply in the hydrophobic outer membrane and failure to form the tubular MAC render C9 sensitive to proteolytic cleavage $(7,47,48)$. We found by SDS-PAGE analysis that surface-bound C 9 molecules were associated with SDS-resistant, high molecular weight complexes, consistent with $\mathrm{C} 9$ polymers in the tubular form of the MAC (47). However, fewer tubular MACs were present on $S$. typhimurium strains with $r c k$.

Using sucrose density gradient ultracentrifugation of detergent-extracted bacterial outer membranes, we found that $r c k$ was associated with a shift from high molecular weight $\mathrm{C} 5 \mathrm{~b}-\mathrm{C} 9$ complexes to a lower molecular weight form. The high molecular weight complexes from $S$. typhimurium without rck migrated as a single, sharp, asymmetrical peak, similar to that seen with serum sensitive $N$. gonorrhoeae, believed to represent the fully polymerized MAC (39). In contrast, $S$. typhimurium strains with $r c k$ showed two distinct $\mathrm{C} 9$-containing high molecular weight peaks, a smaller one comigrating with the presumed MAC peak in the serum-sensitive strains and a larger peak running at a lower molecular weight. Both forms of C9containing complexes were precipitated by a mouse monoclonal antibody that recognizes an epitope of the SC $5 \mathrm{~b}-9$ complex, indicating that even the lower molecular weight material contained recognizable C5b-9 complexes. This was confirmed by showing that the antibody also precipitated $\mathrm{C} 5$ from the same peaks. However, the lower molecular weight form of C5b-9, found only on strains expressing Rck, was dissociated by SDS and migrated on PAGE as monomeric C9. The predominant higher molecular weight form of C5b-9 extracted from the serum-sensitive strain without $r c k$ was not dissociated by SDS and migrated as a high molecular weight band. SDS resistance of $\mathrm{C} 9$ in $\mathrm{C} 5 \mathrm{~b}-9$ complexes has been shown to be a consequence of the formation of tubular polymerized C9; other forms of polymerized C9 (linear or incomplete rings) are dissociated by SDS to monomeric C9 (47).

Our findings indicate that the Rck protein alters the molecular configuration of polymerized C9 associated with the C5b-9 complex on the bacterial surface. Rck is associated with a shift toward the formation of lower molecular weight C5b-9 complexes, in which $\mathrm{C} 9$ either does not form polymers (e.g., C5b$9_{1}$ ) or forms linear polymers or incomplete rings sensitive to SDS dissociation. The latter seems more likely, since the shoulder from the serum-sensitive strain that comigrates with the unique $r c k$ peak contains SDS-resistant poly $C 9$, suggesting that the C5b-9 in this region of the gradients contain multiple C9 molecules. In addition, the mouse monoclonal antibody to SC5b-9 that immunoprecipitates the $\mathrm{C} 9$ in the $r c k$ peak is believed to recognize conformationally altered $C 9$ molecules present in polymerized C9 (Ibarra, K., personal communication).

The precise molecular form of the terminal MAC required for complement-mediated killing of bacteria is unknown. Although some studies have suggested that $\mathrm{C} 5 \mathrm{~b}-8$ alone may produce slow bacteriolysis ( 51 ), the binding of multiple molecules of $\mathrm{C} 9$ to the surface $\mathrm{C} 5 \mathrm{~b}-8$ complex appear to be required for rapid and efficient killing of both $E$. coli and $S$. typhimurium $(44-46,52,53)$. Sequential C9 polymerization is associated with expression of hydrophobic binding sites (54), stable insertion in the outer membrane (55), increased outer membrane permeability $(46,53,56)$, dissipation of the cytoplasmic transmembrane potential $(45,53,57,58)$, and membranolysis ( 55 , $59)$. However, it is uncertain whether bacterial killing requires the formation of circularly polymerized C9 resistant to SDS 
(the classical ring structure of the MAC). Thrombin-cleaved C9, which can form linear but not circular C9 polymers, is capable of killing rough $E$. coli strains in vitro (58). However, mutationally altered regions of $S$. typhimurium outer membrane LPS, regions that render these bacteria susceptible to complement-mediated killing, show evidence of preferential deposition of tubular poly $C 9(60)$. It has been suggested that the ability of complement to form detergent and protease resistant tubular complexes may prevent degradation by bacterial products and enzymes (47).

Rck-mediated serum resistance may be due directly to inhibition of tubular MAC formation and insertion; alternately, the failure to form tubular MAC may reflect a more general effect on $\mathrm{C} 9$ polymerization. In either case, the Rck effect on C9 polymerization in the bacterial membrane represents a novel mechanism of serum resistance in Salmonella.

Detailed studies in Salmonella minnesota indicated that long $\mathrm{O}$ antigen side chains induced $\mathrm{C} 3$ deposition and subsequent formation of the C5b-9 MAC at a site distant from the complement-susceptible hydrophobic portion of the outer membrane $(6,7)$. The C5b-9 complex was found to be associated with the long-chain LPS by weak ionic/hydrophilic interactions; the complex was found to spontaneously dissociate from the outer membrane over time and to be susceptible to elution by high salt solutions. Rck-mediated serum resistance occurs by a mechanism independent of LPS, and the effect is seen in both rough and smooth LPS strains.

Stable binding of the MAC to the bacterial membrane without lysis or death has been reported with certain serum-resistant strains of Neisseria gonorrhoeae $(39,48,49)$. Joiner et al. (39) found evidence that nonbactericidal C5b-9 was associated with bacterial outer membrane constituents, was trypsin sensitive, and ran on sucrose density gradients as complexes of higher molecular weight than did the bactericidal MAC formed on the serum sensitive strain. They postulated that the MAC was associated with an outer membrane protein. Although Rck also appears to permit the formation of stably bound, nonbactericidal C5b-9 complexes, we found that these complexes ran at a lower molecular weight than the MACs on serum-sensitive strains. The most likely explanation for these findings is that C9 does not fully polymerize in the presence of Rck.

Rck does not completely inhibit the formation of intact MACs, as indicated by the presence of some covalently bound ${ }^{125} \mathrm{I}-\mathrm{C} 9$ that sediments as high molecular weight complexes in $r c k$-containing strains. Despite the formation of these intact MACs, however, our $S$. typhimurium strains with $r c k$ remain completely serum resistant. These MACs could represent complete C5b-9 complexes that are associated with LPS side chains and are therefore not bactericidal (6).

We postulate that because Rck is an outer membrane protein it acts only on those complement components that reach the hydrophobic portion of the outer membrane that lies beneath the LPS side chains. In wild-type smooth strains, more C5b-9 complexes interact with LPS than in rough strains (6, 7). Nevertheless, even in smooth bacteria some C5b-9 complexes must be effectively inserted into the membrane, given the small but significant loss of viability in 50\% PNHS. Rck in smooth $S$. typhimurium provides complete protection from serum killing mediated by these complexes and probably shifts the form of these complexes to the lower molecular weight SDS-sensitive complex (Fig. $5 B$ ), as it does in the rough strains
(Fig. $5 A$ ). However, since the bulk of the bound C5b-9 in smooth strains is associated with LPS, the effect of Rck on altering these complexes is partially obscured.

$r c k$ is clearly different from the other plasmid-encoded loci reported to affect the survival or growth of Salmonella serotypes in serum. Sequence analysis demonstrates that Rck is not similar to the TraT-like protein encoded by the S. typhimurium virulence plasmid nor are any of the characteristic 10-bp $r s k$ direct repeats present in the $r c k$ gene (13). Southern hybridization studies detect homologous regions on the virulence plasmids of S. enteritidis and S. dublin (data not shown). However, the region homologous to $r c k$ on the $S$. dublin virulence plasmid pSDL2 maps outside of the locus affecting LPS side chain structure described by Kawahara et al. (16); in addition, Terakado et al. (17) did not find any homology to this locus on virulence plasmids of $S$. typhimurium LT2 strains (17). Furthermore, LPS composition is not altered by the cloned $r c k$ gene (18).

Sequence analysis of $r c k$ revealed a striking similarity to a family of outer membrane proteins in Enterobacteriaceae, consisting of Ail, PagC, Lom, and OmpX (21, 24, 61, 62). The Ail protein, encoded by the Yersinia enterocolitica chromosome, was originally selected for its ability to confer epithelial cell invasion properties on $E$. coli (22). Recent evidence indicates that Ail and Rck share similar serum resistance phenotypes when cloned in E. coli or Salmonella strains and that Rck enhances the ability of $E$. coli to invade epithelial cell lines (Heffernan, E., and J. Bliska, unpublished data). The serum resistance and invasion phenotypes of PagC and OmpX have not been reported. However, the complement resistance property of Rck is not shared by Lom, despite comparable expression and localization in the outer membrane (reference 62 ; Heffernan, E., unpublished data). This result indicates that the serum resistance phenotype is not a nonspecific effect of this family of outer membrane proteins. Significantly, homology analysis indicates that Lom is the most distantly related member of this protein family (18).

\section{Acknowledgments}

We thank Ms. Annette Wunderlich, Mr. Scott Herdman, and Mr. Ken Hirata for expert technical assistance. We also thank Drs. Barbara Matthews, Virginia Waters, Martin Krause, Elizabeth Ziegler, and Charles Davis for helpful discussions and encouragement.

This work was supported in part by Public Health Service Program Project Grant AM-35108 from the National Institutes of Health, a grant from the Veterans Affairs Research Service, and Clinical Investigator Award MID 1 K08 AI01043-01 from the National Institute of Allergy and Infectious Diseases.

\section{References}

1. Taylor P. W. 1983. Bactericidal and bacteriolytic activity of serum against gram-negative bacteria. Microbiol. Rev. 47:46-83.

2. Joiner K. A. 1988. Complement evasion by bacteria and parasites. Annu Rev. Microbiol. 42:201-230.

3. Fierer J., F. Finley, and A. I. Braude. 1974. Release of ${ }^{51} \mathrm{Cr}$-endotoxin from bacteria as an assay of serum bactericidal activity. J. Immunol. 112:2184-2189.

4. Roantree, R. J., and L. A. Rantz. 1960. A study of the relationship of the normal bactericidal activity of human serum to bacterial infection. J. Clin. Invest. $39: 72-81$.

5. Brooks, G. F., K. S. Israel, and B. H. Petersen. 1975. Serum bactericidal and opsonic antibodies in disseminated gonococcal infections. Clin. Res. 23:301-307.

6. Joiner, K. A., C. H. Hammer, E. J. Brown, R. J. Cole, and M. M. Frank 1982. Studies on the mechanism of bacterial resistance to complement-mediated killing. I. Terminal complement components are deposited and released from 
Salmonella minnesota S218 without causing bacterial death. J. Exp. Med. 155:797-808.

7. Joiner, K. A., C. H. Hammer, E. J. Brown, and M. M. Frank. 1982. Studies on the mechanism of bacterial resistance to complement-mediated killing. II. C8 and $\mathrm{C} 9$ release $\mathrm{C} 5 \mathrm{~b} 67$ from the surface of Salmonella minnesota $\mathrm{S} 218$ because the terminal complex does not insert into the bacterial membrane. J. Exp. Med. 155:809-819.

8. Pluschke, G., J. Mayden, M. Achtman, and R. P. Levine. 1983. Role of the capsule and the $\mathrm{O}$ antigen in resistance of $014: \mathrm{K} 1$ Escherichia coli to complement mediated killing. Infect. Immun. 42:907-913.

9. Joiner, K. A. 1986. Studies on the mechanism of bacterial resistance to complement-mediated killing and on the mechanism of action of bacterial antibody. Curr. Top. Microbiol. Immunol. 121:99-133.

10. Gulig P. A. 1990. Virulence plasmids of Salmonella typhimurium and other Salmonellae. Microb. Pathog. 8:3-11.

11. Krause, M., C. Roudier, J. Fierer, J. Harwood, and D. Guiney. 1991. Molecular analysis of the virulence locus of the Salmonella dublin plasmid pSDL2. Mol. Microbiol. 5:307-317.

12. Rhen, M., and S. Sukupolvi. 1988. The role of the traT gene of the Salmonella typhimurium virulence plasmid for serum resistance and growth within liver macrophages. Microb. Pathog. 5:275-285.

13. Vandenbosch, J. L., D. K. Robert, D. R. Kurlandsky, and G. W. Jones. 1989. Sequence analysis of $r s k$, a portion of the 95 kilobase plasmid of Salmonella typhimurium associated with resistance to the bactericidal activity of serum. Infect. Immun. 57:850-857.

14. Vandenbosch, J. L., D. R. Kurlandsky, R. Urdangaray, and G. W. Jones. 1989. Evidence of coordinate regulation of virulence in Salmonella typhimurium involving the $r s k$ element of the 95-kilobase plasmid. Infect. Immun. 57:25662568.

15. Terakado, N., T. Hanaoka, and H. Danbara. 1988. Plasmid-mediated serum resistance and alterations in the composition of lipopolysaccarides in Salmonella dublin. J. Gen. Microbiol. 134:2089-2093.

16. Kawahara K., T. Hamaoka, S. Suzuki, M. Nakamura, S. Y. Murayama, T. Arai, N. Terakado, and H. Danbara. 1989. Lipopolysaccharide alteration mediated by the virulence plasmid of Salmonella. Microb. Pathog. 7:195-202.

17. Terakado, N., T. Ushijima, T. Samejima, H. Ito, T. Hamaoka, S. Murayama, K. Kawahara, and H. Danbara. 1990. Transposon insertion mutagenesis of a genetic region encoding serum resistance in an $80 \mathrm{~kb}$ plasmid of Salmonella dublin. J. Gen. Microbiol. 136:1833-1838.

18. Hackett, J., P. Wyk, P. Reeves, V. Mathan. 1987. Mediation of serum resistance in Salmonella typhimurium by an 11 kilodalton polypeptide encoded by the cryptic plasmid. J. Infect. Dis. 155:540-549.

19. Heffernan, E. J., J. Harwood, J. Fierer, and D. Guiney. 1992. The Salmonella typhimurium virulence plasmid complement resistance gene $r c k$ is homologous to a family of virulence-related outer membrane protein genes including pagC and ail. J. Bacteriol. 174:84-91.

20. Miller, S. I., A. M. Kukral, and J. Mekalanos. 1989. A two component regulatory system (phoPphoQ) controls $S$. typhimurium virulence. Proc. Natl. Acad. Sci. USA. 86:5054-5058.

21. Pulkinnen, W. S., and S. I. Miller. 1991. A Salmonella typhimurium virulence protein is similar to a Yersinia enterocolitica invasion protein and a bacteriophage lambda outer membrane protein. J. Bacteriol. 173:86-93.

22. Miller, V. L., and S. Falkow. 1988. Evidence for two genetic loci in Yersinia enterocolitica that can promote invasion of epithelial cells. Infect. Immun. 56:1242-1248.

23. Miller, V. L., J. J. Farmer III, W. E. Hill, and S. Falkow. 1979. The ail locus is found uniquely in Yersinia enterocolitica commonly associated with disease. Infect. Immun. 57:121-131.

24. Miller, V. L., J. B. Bliska, and S. Falkow. 1990. Nucleotide sequence of the Yersinia enterocolitica ail gene and characteristics of the Ail protein product. $J$. Bacteriol. 172:1062-1069.

25. Cohen, S. M., A. Chang, and L. Hus. 1972. Non-chromosomal antibiotic resistance in bacteria: genetic transformation of Escherichia coli by R-factor DNA. Proc. Natl. Acad. Sci. USA. 69:2110-2114.

26. Beninger, P. R., G. Chikami, J. Tanabe, C. Roudier, J. Fierer, D. G. Guiney. 1988. Physical and genetic mapping of the Salmonella dublin virulence plasmid pSD12. Relationship to plasmids from other Salmonella strains. J. Clin. Invest. 81:1341-1347.

27. Tinge, S. A., and R. Curtiss III. 1990. Isolation of the replication and partitioning regions of the Salmonella typhimurium virulence plasmid and stabilization of hetrologons replicons. J. Bacteriol. 172:5266-5277.

28. Roudier, C., M. Krause, J. Fierer, and D. G. Guiney. 1990. Correlation between the presence of sequences homologous to the vir region of the $S$. dublin plasmid pSDL2 and the virulence of twenty-two Salmonella serotypes in mice. Infect. Immun. 58:1180-1185.

29. McCutchan, J. A., S. Levine, and A. I. Braude. 1976. Influence of colony type on susceptibility of gonococci to killing by human serum. J. Immunol. 116:1652-1655.
30. Vandenbosch, J. L., D. K. Robert, and G. W. Jones. 1987. Plasmid-associated resistance of Salmonella typhimurium to complement activated by the classical pathway. Infect. Immun. 55:2645-2652.

31. Kabat, E. A., and M. M. Mayer. 1961. Experimental Immunochemistry. Charles C. Thomas, Springfield, IL. 567 pp.

32. Fraker, P. J., and Y. C. Speck. 1978. Protein and cell membrane iodinations with a sparingly soluble cholramide 1,3,4,6-6-tetrachloro-3a, 6a-diphenylglycouril. Biochem. Biophys. Res. Commun. 80:849-857.

33. Kitamura, F., K. Shimada, T. Suzuki, and K. Nichioka. 1985. A simplified method for the preparation of EAC14 intermediate cells using human serum treated with methylprednisolone. J. Immunol. Methods. 85:363-370.

34. Polley, M. J., and H. J. Muller-Eberhard. 1967. Enhancement of the hemolytic activity of the second component of human complement by oxidation. J. Exp. Med. 126:1013-1025.

35. Cooper, N. R., and H. J. Muller-Eberhard. 1970. The reaction mechanism of human C5 in immune hemolysis. J. Exp. Med. 132:775-784.

36. Tschopp, J. 1984. Circular polymerization of the membranolytic ninth component of complement. Dependence of metal ions. J. Biol. Chem. 259:10559-10563.

37. Laemmli, U. K. 1970. Cleavage of structural proteins during the assembly of bacteriophage T4. Nature (Lond.). 227:680-685.

38. Puentes, S. M., D. L. Sacks, R. P. DaSilva, and K. A. Joiner. 1988. Complement binding by two developmental stages of Leishmania major promastigotes varying in expression of a surface lipophosphoglycan. J. Exp. Med. 167:887-902.

39. Joiner, K. A., K. A. Warren, E. J. Brown, J. Swanson, and M. M. Frank. 1983. Studies on the mechanism of bacterial resistance to complement-mediated killing. IV. C5b-9 forms high molecular weight complexes with bacterial outer membrane constituents on serum resistant but not on serum-sensitive Neiserria gonorrhoeae. J. Immunol. 131:1443-1451.

40. Francoeur, A. M., C. L. Peebles, P. T. Gomper, and E. M. Tan. 1986. Identification of $\mathrm{Ki}(\mathrm{Ku} . \mathrm{p} 70 / \mathrm{p} 80)$ autoantigens and analysis of anti-Ki autoantibody reactivity. J. Immunol. 136:1648-1653.

41. Mendenhall, W. 1975. Introduction to Probability and Statistics. Wadsworth Publishing Company, Inc., Belmont, CA. 457 pp.

42. Goldman R. C., K. Joiner, and L. Leive. 1984. Serum-resistant mutants of Escherichia coli 0111 contain increased lipopolysaccharide, lack an $\mathrm{O}$ antigencontaining capsule, and cover more of their lipid A core with $\mathrm{O}$ antigen. $J$. Bacteriol. 159:877-882.

43. Podack, E. R., G. Biesecker, W. P. Polb, and H. J. Muller-Eberhard. 1978. The C56-6 complex: reaction with C7, C8, C9. J. Immunol. 121:484-493.

44. Joiner, K. A., A. B. Tartanian, C. H. Hammer, and J. E. Schwenle. 1989. Multimeric C9 within C5b-9 deposits in unique locations in the cell wall of $S$. typhimurium. J. Immunol. 142:4450-4457.

45. McKay, S. L. D., and J. R. Dankert. 1990. Bacterial killing and inhibition of inner membrane activity by C5b-9 complexes as a function of the sequential addition of C9 to C56-8 sites. J. Immunol. 145:3367-3371.

46. Bhakdi, S., G. Kuller, M. Mubly, S. Fromm, G. Seibert, and J. Pamisius. 1987. Formation of transmmural complement pores in serum-sensitive Escherichia coli. Infect. Immun. 55:206-210.

47. Padack, E. R., and J. Tschapp. 1982. Circular polymerization of the ninth component of complement. J. Biol. Chem. 257:15204-15212.

48. Joiner K. A., K. A. Warren, C. Hammer, and M. M. Frank. 1985. Bactericidal but not nonbactericidal C5b-9 is associated with distinctive outer membrane proteins in Neisseria gonorrhoeae. J. Immunol. 134:1920-1925.

49. Harriman, G. R., E. R. Podack, A. I. Braude, L. C. Corbeil, A. F. Esser, and J. G. Curl. 1982. Activation of complement by serum resistant Neisseria gonorrhoeae. Assembly of the membrane attack complex without subsequent cell death. J. Exp. Med. 156:1235-1249.

50. Tschopp, J., E. R. Podack, and H. J. Muller-Eberhard. 1985. The membrane attack complex of complement: C $5 \mathrm{~b}-8$ complex as accelerator of $\mathrm{C} 9$ polymerization. J. Immunol. 134:495-499.

51. Harriman, G. R., A. F. Esser, E. R. Podack, A. C. Wunderlich, A. I. Braude, T. F. Lint, and J. G. Curd. 1981. The role of C9 in complement-mediated killing in Neisseria. J. Immunol. 127:2386-2390.

52. Joiner, J. A., M. A. Schmetz, M. E. Sanders, T. G. Murrary, C. H. Hammer, R. Dourmashlein, and M. M. Frank. 1985. Multimeric complement component $\mathrm{C} 9$ is necessary for killing of Escherichia coli $\mathrm{J} 5$ by terminal attack complex C5b-9. Proc. Natl. Acad. Sci. USA. 2:4808-4812.

53. Bloch, E. F., M. A. Schmetz, J. Foulds, C. H. Hammer, M. M. Frank, and K. Joiner. 1987. Multimeric C9 within C $5 b-9$ is required for inner membrane damage to Escherichia coli J5 during complement killing. J. Immunol. 138:842848.

54. Podack, E. K., G. Biesecker, and H. J. Muller-Eberhard. 1979. Membrane attack complex of complement: generation of high affinity phospholipid binding sites by fusion of five hydrophilic plasma proteins. Proc. Natl. Acad. Sci. USA. 76:897-901.

55. Kroll, H.-P., W.-H. Voight, and P. W. Taylor. 1984. Stable insertion of 
C5b-9 complement complexes into the outer membrane of serum-treated, susceptible Escherichia coli cells as a prerequisite for killing. Zentralbl. Bakteriol. Mikrobiol. Hyg. 258:316-326.

56. Levine, S. D., and R. P. Levine. 1981. How complement kills $E$. coli. 1 Location of the lethal lesion. J. Immunol. 127:1146-1151.

57. Schroder, G., K. Brandenlaug, L. Brade, and U. Seydel. 1990. Pore formation by complement in the outer membrane of gram-negative bacteria studied with asymmetric planar lipopolysaccharide/phospholipid bilayers. J. Membrane Biol. 118:161-170.

58. Dankert, J. R., and A. F. Esser. 1987. Bacterial killing by complement: C mediated killing in the absence of C5b-8. Biochem. J. 244:393-399.

59. Tomlinson, S., P. W. Taylor, B. P. Morgan, and J. P. Luzuo. 1989. Killing of gram-negative bacteria by complement. Fractionation of cell membranes after complement C5b-9 deposition onto the surface of Salmonella minnesota Re565. Biochem. J. 263:505-511.

60. Goldman, R. C., and M. F. Miller. 1989. Complement attack of altered outer membrane areas synthesized after inhibition of the 3-deoxy-D-mannoe-octulosonale pathway leads to cell death. J. Immunol. 142:185-194.

61. Barondess, J. J., and J. Beckwith. 1990. A bacterial virulence determinant encoded by lysogenic coliphage lambda. Nature (Lond.). 346:871-872.
62. Stoorvogel, J., M. J. A. W. M. van Bussel, J. Tommassen, and J. A. M. van de Klundest. 1991. Molecular characterization of an Enterobacter cloacae outer membrane protein (OmpX). J. Bacteriol. 173:156-160.

63. Davis, C. E., S. D. Freedman, H. Douglas, and A. I. Braude. 1969. Analysis of sugars in bacterial endotoxins by gas liquid chromatography. Anal. Bio chem. 28:243-256.

64. Guiney, D. G., P. Hasegawa, and C. E. Davis. 1984. Plasmid transfer from Escherichia coli to Bacteriodes fragilis: differential expression of antibiotic resistance phenotypes. Proc. Natl. Acad. Sci. USA. 81:7203-7206.

65. Luderitz, O., C. Galanos, H. J. Risse, E. Ruschmann, S. Schlecht, G Schmidt, H. Schulte-Holthausen, R. Wheat, O. Westphal, and J. Schlosshard 1966. Structural relationships of Salmonella O and R antigen. Ann. N.Y. Acad. Sci. 133:349-374.

66. Fields, P. I., E. A. Groisman, and F. Heffron. 1989. A Salmonella locus that controls resistance to microbicidal proteins from phagocytic cells. Science (Wash. DC). 243:1059-1061.

67. Fields, P. I., R. V. Swanson, C. G. Haidaris, and F. Heffron. 1986. Mutants of Salmonella typhimurium that cannot survive within the macrophage are avirulent. Proc. Natl. Acad. Sci. USA. 83:5189-5193. 